\title{
Empirical correlation of shear wave velocity (vs) with spt of soils in Madrid
}

\section{Pérez-Santisteban ${ }^{1 *}$, A. Muñoz Martín' ${ }^{2}$ A. Carbó Gorosabel ${ }^{2}$ and J.M. Ruiz Fonticiella ${ }^{3}$ pre- $^{-}$ dict the stiffness and deformability of the soils of Madrid by statistical correlation between Vs measured with the ReMi technique or passive seismic, and the standard penetration test (Nspt).}

E

mpirical correlations are usually used as a predictive tool in geotechnical engineering. However, equations calculated for soils very different to the ones to be characterized are frequently used, and so they are not representative of their mechanical properties. This fact, added to the increasing interest of civil engineering in knowing the shear wave velocity (Vs) of the ground, has led to the calculation of different empirical equations to predict the Vs value of the soils of Madrid. In this study this has been achieved by calculating the empirical correlations between the Vs value obtained through the ReMi (Refraction Microtremor) technique and the Standard Penetration Test (500 $\mathrm{N}_{\mathrm{SPT}}$ values). The empirical correlations proposed are applicable to the whole metropolitan area of Madrid, and have an excellent predictive capability owing to the incorporation of the measurement depth to the equations, which has an important influence in the resistance properties of soils.

It is always better to have data collected in the studied site. But often there are too many difficulties to carry out some of these surveys. It may also happen that the surveys take too long or are too expensive to carry out. In these situ- ations, empiric equations can be used to estimate this data. In geotechnical engineering, these empiric correlations are used frequently as a predictive tool, especially in the project's design primary phases, when vast extensions of terrain are to be characterized in a short period of time, and to define if the soil fits a specific purpose. Because of this factor, there are plenty of estimations published that link between them different types of mechanical properties and geotechnical parameters.

In the last few years, there has been an increasing interest in finding the value of Vs. There are difficulties in estimating its value directly, as it is not always easy to identify the $S$ wave, especially in urban areas, as it may be disguised by ambient noise. These factors have resulted in a great number of correlations that establish the value of Vs according to lithology and other geotechnical parameters. Of all these correlations, clearly the most frequent is the one that links Vs to the results of the Standard Penetration Test (Nstp) [1-21], as it is a much extended and widely used parameter.

These correlations are very useful when no other data directly acquired is available, or when a quick estimation of
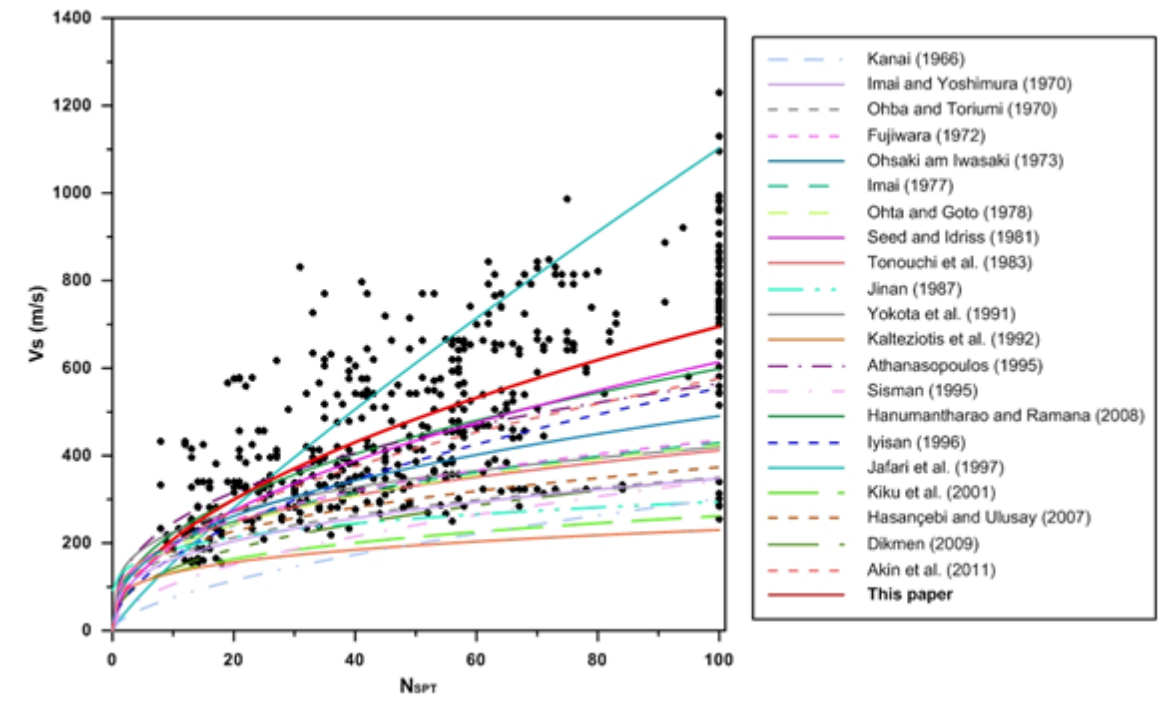

Figure 1 Comparison of the correlation between Vs and NSPT for the soils of Madrid and the equations proposed in the bibliography.

${ }^{1}$ Department of Applied Geophysics, Orbis Terrarum Projects.

${ }^{2}$ Department of Geodynamics, Universidad Complutense de Madrid (UCM).

${ }^{3}$ Laboratorio de Geotecnia (CEDEX).

"Corresponding author, E-mail: iperezs@orbisterrarum.es 
Near Surfare Gencrienre

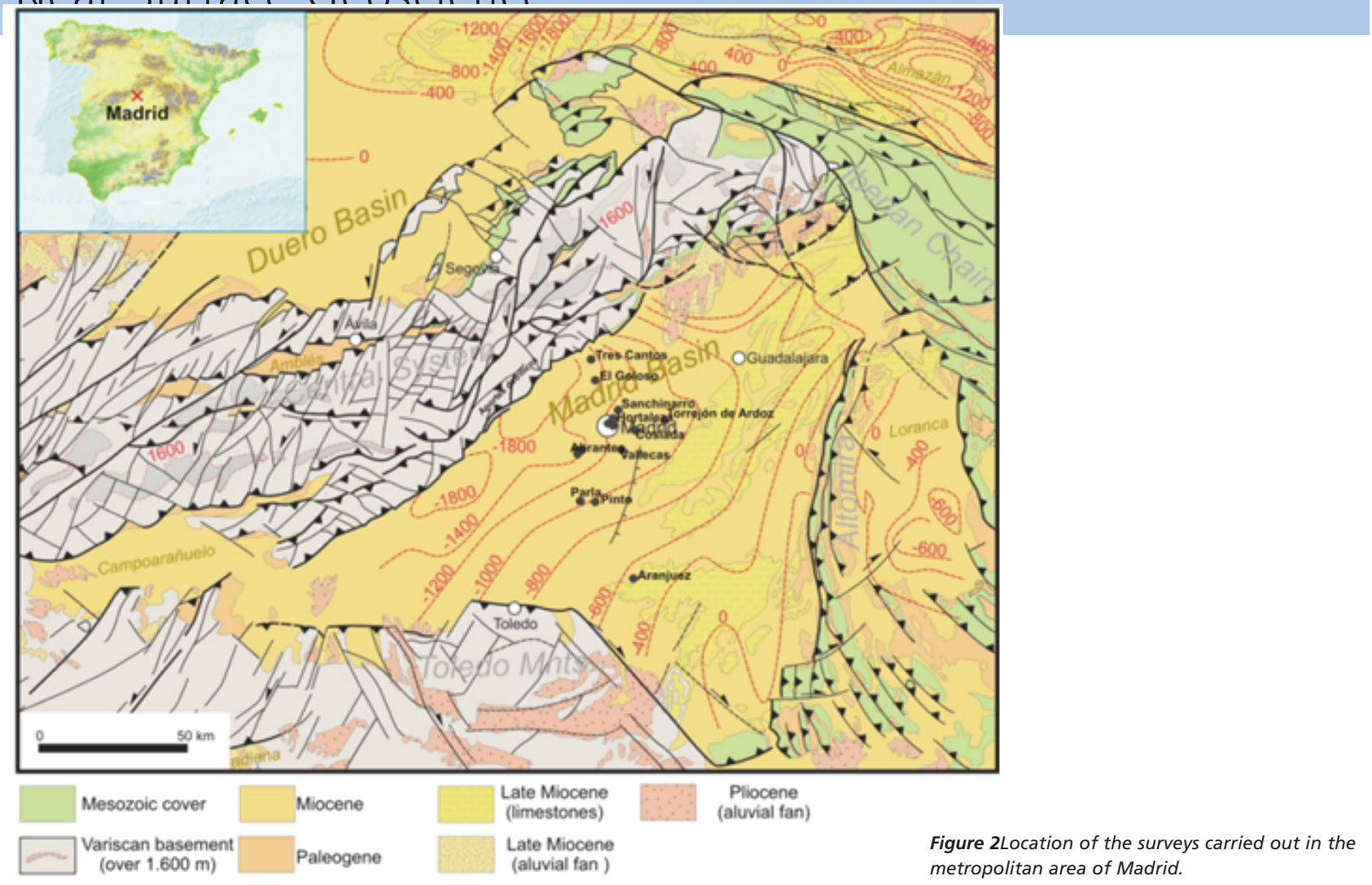

the terrain's geotechnical properties is needed. But it is always important not to forget what geological conditions the correlations were calculated for, and so, if it can be used in the particular situation that is to be characterized. As each area of investigation is characterized by a different geological history, the geotechnical parameters obtained will be conditioned by a history of tensions, lithological compositions, age, etc. This situation implies that the empirical correlations calculated for a specific location may not be valid in other locations. Thus, to be able to obtain reliable and representative parameters of the ground that is to be characterized, it is essential to use equations specifically calculated for that kind of soil and with the same geological conditions.

Therefore, the empiric equations that can be found in the bibliography have been calculated for other kinds of soils, and cannot be used to predict the stiffness of the soils of Madrid. Figure 1 displays a representation of the relation between the values of Vs and SPT measured for this investigation and the most common correlations between these two values published. The figure shows that, except in the case of Jafari et al. (1997) [16], all the correlations from the bibliography calculated very low Vs for the grounds of Madrid. This probably happens because most of these studies investigate quaternary soils and deposits not very consolidated with Vs values much lower than those characteristics of the tertiary soils of Madrid. This demonstrates that there is a big grade of variability in the Vs predicted by the different empiric models, and highlights the need of measuring Vs specifi- cally in every location to be investigated before establishing its predictive equations.

Consequently, to obtain predictive equations suitable for the soils of Madrid, it will be necessary to perform a complete statistical analysis for a sufficiently representative amount of soils samples. This study's goal is to predict the stiffness and deformability of the soils of Madrid. To do so, the statistical correlation between Vs measured with ReMi technique or passive seismic, and the standard penetration test (Nspt) has been analysed.

\section{Geological and geotechnical properties of the soils of Madrid}

The city of Madrid and its urban surroundings is situated in a sedimentary intermountain watershed that was defined during the Tertiary Era when the central system rose. Consequently, its soils are made of Miocene materials that resulted from a sedimentary system based on great alluvial fans that started in the watershed bankside and that converged towards the central zone in an evaporite lake.

Because of this deposition system, the sediments normally distribute in concentric bands with the edging facies constituted by immature arkoses prograding over increasingly argillaceous and gypseous facies in the centre of the basin. This is not as simple as it sounds owing to the discontinuity caused by climate change or to the raising of different margins above the cone which causes episodes of gullies, more or less energetic, which control the granulometry and the progress of the detrital material. These factors provoke 
a pronounced discontinuity in the facies and it is common to find arkoses of different granulometry interbedded with lacustrine deposits.

Therefore, the detrital facies found in Madrid are richer in fines the further we are from the watershed bankside and up to the transition facies. The transition facies are defined by a saline mudflat located between the more distal zone of the fans and central lake, where evaporite minerals can already be found.

It is common in Madrid to refer to the different facies through the following nomenclature, normally used in the geotechnical descriptions and publications:

- Arena de Miga: sand with less than 25\% fines (particles $<0,008 \mathrm{~mm}$ )

- Toscos: Sandy clays or clays with more than $40 \%$ fines.

- Peñuelas: high plasticity clays that correspond to the transition facies.

- Gypsiferous clay: Interbedded clays with gypsums from the evaporite facies.

As per the geotechnical properties of the detrital facies (Arenas de Miga and Toscos), the fines content tends to increase its resistance.

The Peñuelas of the transition facies are the lithology with more variable geotechnical behaviour. Although when healthy they are formed by very resistant lithificated clays, it is common to find them softened and weathered. This lithology also commonly presents calcareous levels associated to the basin's shallowing.

The gypsums of the evaporitie facies are notable for their resistance, but also show different geotechnical problems associated to karstification.

\section{Relationship between Vs and Nspt for the soils of Madrid}

To establish the correlation between the Vs obtained through the ReMi technique in the soils of Madrid and the results of the SPT tests, a statistical analysis between the 500 values of Nspt and the Vs that correspond with the depths tested in the boreholes has been made.

A lineal regression analysis through the method of least squares was used for the statistical analysis, which minimizes the sum of the squared residuals:

$\sum_{i=1}^{n} r_{i}^{2}=\sum_{i=1}^{n}\left(Y_{i}-Y_{i}^{*}\right)^{2}$

$r$ being the residual, which is the difference between the value of the observed variables (Yi) and the value predicted in theory by the regression ( $\left.\mathrm{Yi}^{*}\right)$.

Through the process, we have obtained an empirical relation that is able to predict the Vs values from the results of the SPT tests:

$V S=62.6 \cdot N_{S P T}^{0.52} \quad R^{2}=0.5$
This empirical relation has a coefficient of determination $(R 2)$ of 0.53 . This indicates that only $53 \%$ of Vs values are explained by the Nspt values. This $R 2$ value confirms that there is a lineal relation between these two variables. Nonetheless, it does also confirm that the proposed function is not able to explain nearly half of the Vs data measured in situ.

The empirical relationship between Vs and Nspt for each of the lithological groups is expressed through the following equations:

$$
\begin{array}{ll}
\text { Sands: } V_{s}=98.69 \cdot N_{S P T}^{0.321} & \mathrm{R}^{2}=0.37 \\
\text { Toscos: } V_{s}=44.87 \cdot N_{S P T}^{0.606} & \mathrm{R}^{2}=0.42 \\
\text { Peñuelas: } V_{s}=60.79 \cdot N_{S P T}^{0.527} & \mathrm{R}^{2}=0.58 \\
\text { Gypsiferous clay: } V_{s}=159.43 \cdot N_{S P T}^{0.344} & \mathrm{R}^{2}=0.68
\end{array}
$$

Sands show a very poor correlation between $\mathrm{Vs}$ and $\mathrm{N}_{\mathrm{SPT}}$, improving slightly with the clay content and the consolidation degree. Anyhow, there is not a good correlation between Vs and $\mathrm{N}_{\mathrm{SPT}}$ for any of the lithological groups, and all the coefficients of determination are below $0.7\left(\mathrm{R}^{2}<0.7\right)$. This shows that the Vs cannot be explained only in terms of SPT, so the need to include another parameter in the equation has to be considered.

We know that the Vs is subject to depth, as it controls the consolidation degree and the confining tension of the soils. Therefore, the residual values of the equations ( $r$ ) have to be analysed, namely, the difference between the value of the variable measured experimentally and the theoretical

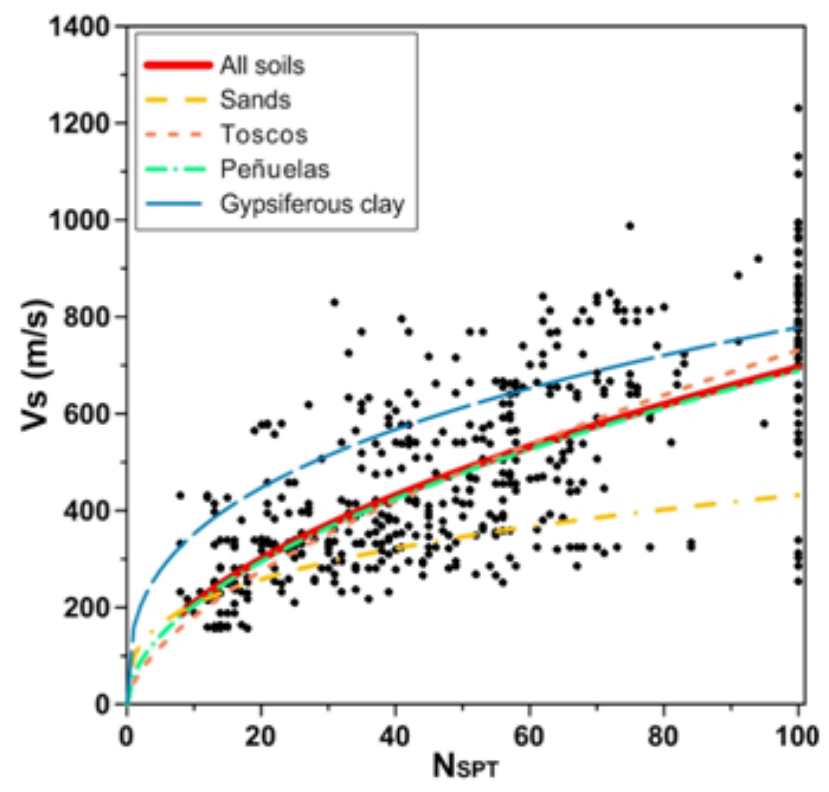

Figure 3 Correlation between VS and Nspt for the soils of Madrid. 


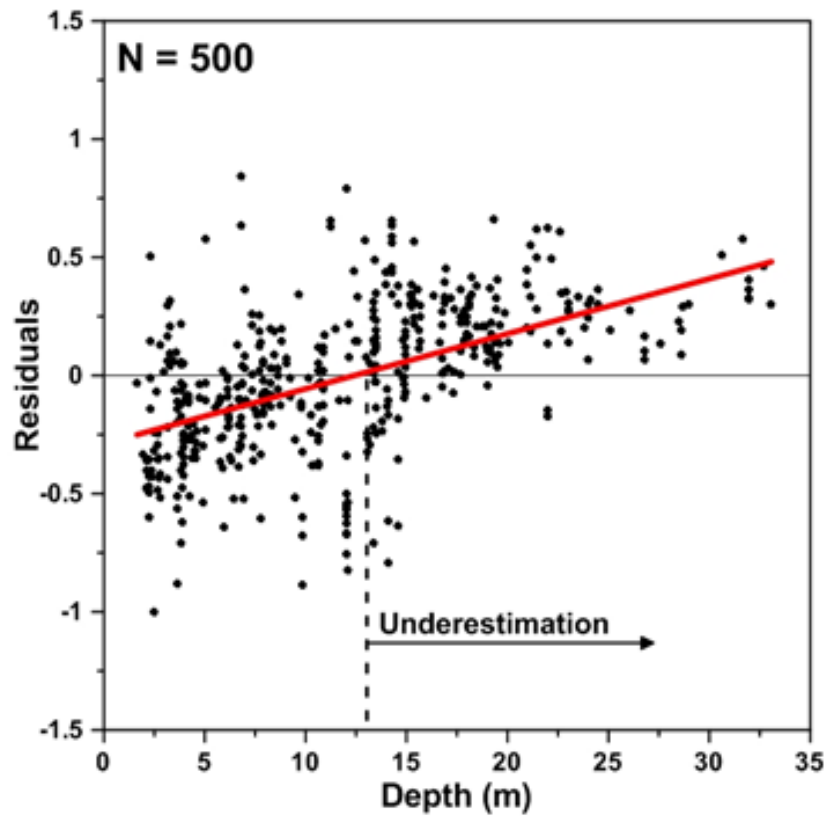

Figure 4 Graphic of the residuals of equation 6 versus depth (omitted variable).

value calculated by the correlation equation. By measuring these residual values the predictive capability of the equations can be studied, and we can determine if they have a bias.

\section{Depth influence}

If we compare the residuals of equation 5 versus depth $(Z)$, it shows that there is an evident positive lineal tendency of the residuals with depth (Figure 4). This indicates that the errors rest on this variable that was not taken into consideration.

Residuals are positive for high depths. This indicates that the Vs calculated with this relation for depths of more than 12 metres are underestimated. This demonstrates that the previous equations introduce a bias, and that to assure

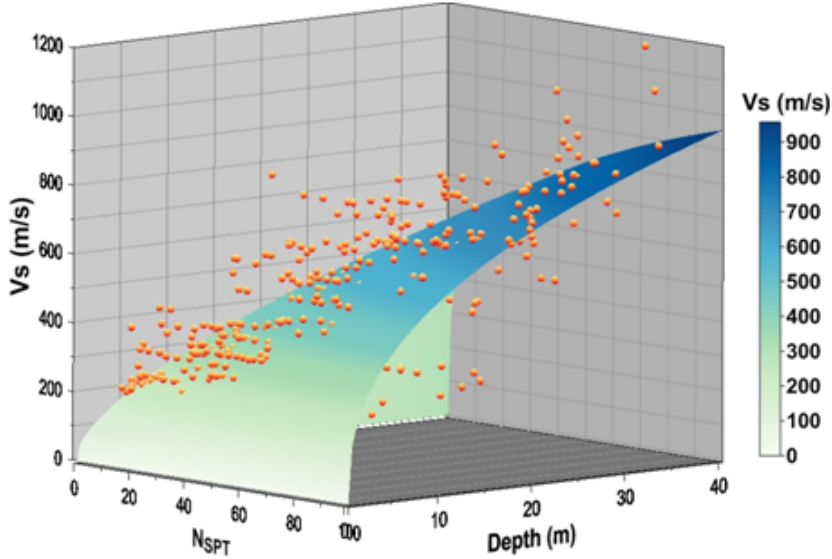

Figure 5 Model showing the relation between Vs with depth and the Nspt values. the errors' independence, depth has to be included in the analysis.

If the measuring depth is included in the equations, the quality of the correlations increases significantly, the experimental data adjusts better to the regression equation, and the coefficient of determination increases for all lithologies (Figure 5):

$$
\begin{array}{ll}
\text { All soils: } V_{s}=77.85 \cdot N_{S P T}^{0.121} \cdot Z^{0.619} & \mathrm{R}^{2}=0.76 \\
\text { Sands: } V_{s}=77.85 \cdot N_{S P T}^{0.121} \cdot Z^{0.619} & \mathrm{R}^{2}=0.78 \\
\text { Toscos: } V_{s}=110 \cdot N_{S P T}^{0.147} \cdot Z^{0.397} & \mathrm{R}^{2}=0.72 \\
\text { Peñuelas: } V_{s}=60.59 \cdot N_{S P T}^{0.213} \cdot Z^{0.479} & \mathrm{R}^{2}=0.77 \\
\text { Gypsiferous clays: } V_{s}=128.67 \cdot N_{S P T}^{0.273} \cdot Z^{0.188} \quad \mathrm{R}^{2}=0.82
\end{array}
$$

\section{Analysis of predictive capability}

Usually to rate the quality of the regression function, the coefficient of determination is used $\left(\mathrm{R}^{2}\right)$. It represents the percentage of variability of Vs explained by the regression function. Its value fluctuates between 0 when the independent variables do not explain the variations in Vs, and 1 when it fits perfectly.

Nevertheless, a regression model with a high percentage of explained variations may not have a high predictive capacity. This means that the percentage of data not explained can have a value very different from the one predicted by the equation.

Therefore, for a correct statistical analysis, it is necessary to analyse the residual values of the equation, and study the predictive capability of the proposed correlations. This way, for all the equations posed, a percentage error on the estimated Vs has been calculated:

$\operatorname{Error}(\%)=\left(\left(V_{S c}-V_{S m}\right) / V_{S m}\right) \cdot 100$

where Vsc is the speed calculated by the equation, and Vsm is the speed calculated experimentally through the ReMi technique.

The relative error for the Vs estimation (equation 15) was calculated to analyse the security level of the empiric correlations used to predict the Vs. The results are shown in relation to cumulative frequency (Figure 6).

This figure shows that $73 \%$ of Vs values calculated through the equation that links all soils of Madrid (equation 12 ) have an error of less than $20 \%$ with regard to the measured Vs.

When applying the same analysis to the different lithological groups, $80 \%$ of the values calculated by equations 13 and 14 for sands (Arena de Miga) and toscos have an error of less that $20 \%$ with regard to the measured Vs. 
However, for peñuelas, the predictive capability of the equation is lower. Only $60 \%$ of the Vs values calculated show an error of less than $20 \%$. For clays with gypsum, $85 \%$ of the Vs values calculated with equation 16 show an error of less than $20 \%$.

\section{Depth influence in the prediction of the stiffness of soils}

In the empiric correlations analysed, it has been demonstrated that to predict the stiffness and the deformability of the soils of Madrid it is necessary to include in the equations the depth measuring point. If the depth is not included as an explanatory variable, the values of Vs calculated below 10-12 metres depth are underestimated. This happens because the compaction of soils owing to the weight of the overlying materials is not taken into account. It has also been demonstrated that to assure the independence in the predictive equation's error, it is necessary to include the depth measuring point in the correlations.

In all correlations, Vs is subject to depth and lithology (percentage of fines, age, cementation, grade of overconsolidation, etc.). For the analysed equations, the influence of depth is stronger in sands, and it diminishes as the amount of fines increases, or cementation levels rise. This is owing to sands not being pre-consolidated, and consequently easier to compact than other lithologies. This lithological group barely has cohesion or cementation, and so its Vs values basically depend of the depth measuring point. For this reason, the correlations of this lithological group are the improved when this variable is included in the equations.

As for Toscos, depth still has an important influence on the stiffness. But Vs is also affected by other factors related to the clay content, as cohesive forces or saturation grade.

The influence of depth on Peñuelas is small, because it is lithified clay difficult to compact and also very variable depending on the saturation and cementation grade. Lastly, as for the clays with gypsums, depth barely has any influence on stiffness, especially if the gypsiferous levels are high.

\section{Conclusions}

Empiric correlations are a very useful tool for estimating the different geotechnical parameters when other direct tests are not available. They always need to be used as a measure, and their limits have to be known. It is indispensable to use equations calculated for the same soils that are to be characterized, and if possible, based on its lithology.

The correlations presented in this study were calculated for number of parameters sufficiently representative of all the lithologies and at different depths. Consequently, these equations can be extrapolated to all soils of Madrid, and can be used as an efficient predictive tool to calculate Vs variations in the metropolitan area. All the correlation equa-

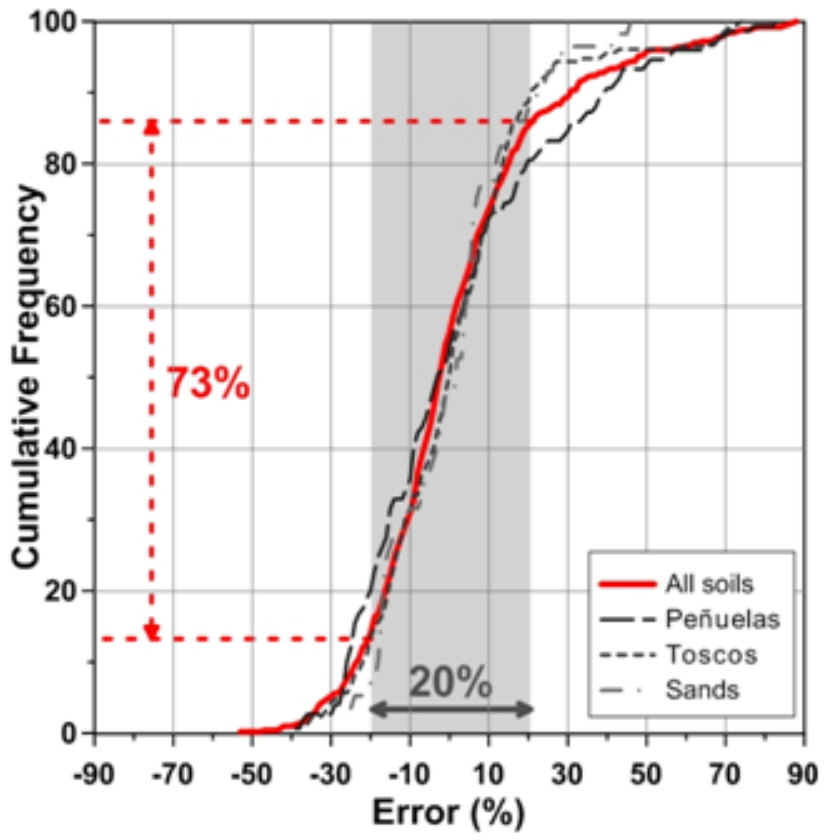

Figure 6 Analysis of the predictive capability of the correlation between Vs, Nspt and depth for all soils of Madrid.

tions (except for Peñuelas) also have an excellent predictive capability, with more than $70 \%$ of the calculated parameters having an error of less than $20 \%$ as regard to the measured in situ.

The equations for the Peñuela facies lithology have proved to be the less predictable ones. This is because of the variability of its geotechnical properties. Its Vs is very sensible to the variability in resistance that distinguishes its lithological group, detecting changes in cementation and weathering when they have enough thickness. However, the same does not happen with other analysed parameters $\left(Z, N_{S P T}\right)$, which are not able to explain the variation of Vs either because of the difference in measuring scale or because of the different factors that control each parameter.

The influence of depth has been analysed, and it has been demonstrated that it is an indispensable parameter for predicting the stiffness of soils. The soils under high confining tensions behave as more rigid materials than identical soils under less confining tensions. The influence of depth is also greater in the younger lithologies, with less cohesion, pre-consolidation and without diagenesis. The analysis questions if a bias has been introduced in the published equations that correlate Vs directly to other geotechnical parameters, which would also explain the important difference between them.

\section{Acknowledgements}

The geotechnical data and the locations for the fields tests were made possible by the generosity of a number of 
companies. The authors would like to thank María Milián from GMC Ingenieria, Raúl Martín from Progeotec, José Ramón Negueruela from Tragsatec, Alicia Aguilera from Segeyco S.A. Luis Sopeña and Fernando Puell and Joaquín Dorronsoro from Orbis Terrarum.

\section{References}

Andrus, R.D., Piratheepan, P., Ellis, B.S., Zhang, J. and Juang, C.H. [2004]. Comparing Liquefaction Evaluation Methods using Penetration-Vs relationships. Soil Dynamics and Earthquake Engineering, 24, 713-721.

Akin, M.K., Kramer, S.L., Topal, T. [2011]. Empirical correlations of shear wave velocity (Vs) and penetration resistance (SPT-N) for different soils in an earthquake-prone area (Erbaa-Turkey). Engineering Geology, 119, 1-17.

Athanasopoulos, G.A. [1995]. Empirical correlations Vs-N SPT for soils of Greece: a comparative study of reliability. $7^{\text {th }}$ International Conference on Soil Dynamics and Earthquake Engineering, 19-36.

Bellana, N. [2009]. Shear Wave Velocity as function of SPT Penetration resistance and vertical effective stress at California Bridge sites. MSc Thesis, University of California, Los Angeles.

Das, B.M. [2001]. Principles of Foundation Engineering. California State University, Sacramento, USA.

Dikmen, U. [2009]. Statistical correlations of shear wave velocity and penetration resistance for soils. Journal of Geophysics and Engineering, 6, 61-72.

Fujiwara T. [1972]. Estimation of ground movements in actual destructive earthquakes. Fourth European Symposium on Earthquake Engineering, 125-132.

Hasançebi, N. and Ulusay, R. [2007]. Empirical correlations between shear wave velocity and penetration resistance for ground shaking assessments. Bulletin of Engineering Geology and the Environment, 66, 203-213.

Hanumantharao, C. and Ramana, G.V. [2008]. Dynamic soil properties for microzonation of Delhi, India. Journal of Earth System Science, 117 (2), 719-730.

Imai, T. and Yoshimura, Y. [1970]. Elastic wave velocity and soil properties in soft soil. Tsuchito-Kiso, 18 (1), 17-22.

Imai, T. [1977]. P and S wave velocities of the ground in Japan. IX International Conference on Soil Mechanics and Foundation Engineering, 2, 127-132.

Iyisan, R. [1996]. Correlations between shear wave velocity and in-situ penetration test results. Teknik Dergi, 7 (2), 1187-1199.
Jafari, M.K. [1997]. Empirical correlation between shear wave velocity (Vs) and SPT-N value for south of Tehran soils. $4^{\text {th }}$ International Conference on Civil Engineering, Abstracts.

Jinan, Z. [1987]. Correlation between seismic wave velocity and the number of blow of SPT and depth. Chinese Journal of Geotechnical Engineering, 92-100.

Kalteziotis, N. [1992]. Evaluation of dynamic characteristics of Greek soil formations. Second Hellenic Conference on Geotechnical Engineering, 2, 239-246.

Kanai, K. [1966]. Conference on Cone Penetrometer. The Ministry of Public Works and Settlement, Ankara, Turkey.

Kiku, H. [2001]. In-situ penetration tests and soil profiling in Adapazari, Turkey. ICSMGE/TC4 Satellite Conference on Lessons Learned From Recent Strong Earthquakes, 259-265.

Ohsaki, Y, Iwasaki R. [1973]. On dynamic shear moduli and Poisson's ratio of soil deposits. Soil and Foundations, 13 (4), 61-73.

Ohba, S. and Toriumi, I. [1970]. Dynamic response characteristics of Osaka Plain. Annual Meeting, A.I.J, Abstracts.

Ohta, Y. and Goto, N. [1978]. Empirical shear wave velocity equations in terms of characteristic soil indexes. Earthquake Engineering and Structural Dynamics, 6, 167-187, Doi:10.1002/eqe. 4290060205.

Pérez-Santisteban, I. [2012]. Caracterización geotécnica de los suelos de Madrid mediante la técnica ReMi: Aplicaciones en la ingeniería civil. MSc Thesis, Universidad Complutense de Madrid, Madrid.

Rodríguez, J.M. [2000]. Propiedades geotécnicas de los suelos de Madrid. Revista de Obras Públicas, 3405, 59-84.

Seed, H.B. and Idriss, I.M. [1981]. Evaluation of liquefaction potential sand deposits based on observation of performance in previous earthquakes. ASCE National Convention (MO), 481544.

Sisman, H. [1995]. An investigation on relationships between shear wave velocity, and SPT and pressuremeter test results. MSc Thesis, Ankara University, Ankara.

Tonouchi, K. [1983]. S wave velocity in the ground and the damping factor. Bulletin of Engineering Geology and Environment, 26-27 (1), 327-333.

Yokota, K. [1991]. Dynamic deformation characteristics of soils determined by laboratory tests. OYO Technical Report, 3, 13-37.

Yoshida, Y. and Motonori, I. [1988] Empirical formulas of SPT blowcounts for gravelly soils. ISOPT, 1, 381-387.

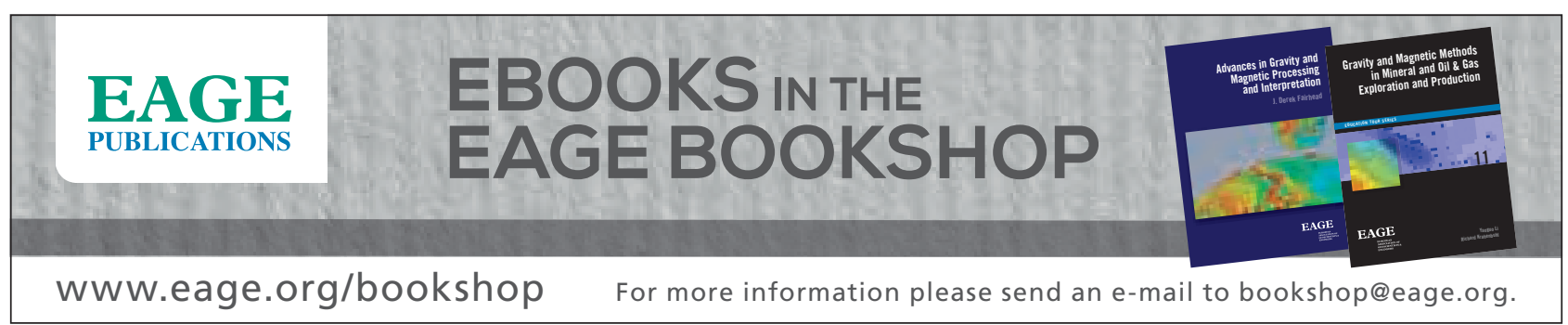

